\title{
Real exchange rate dynamics in the Asian economies: can regime shifts explain purchasing power parity puzzles?
}

\begin{abstract}
We show that the strong version of the purchasing power parity (PPP) hypothesis holds in most of the US dollar real exchange rates using cointegration method that accounts for breaks in the models. The break dates in seven of the Asian currencies coincide with the two rounds of currency depreciation recorded during the 1997-1998 financial crises. We obtain a mean half-life estimate of about 10 months for PPP to converge to its long-run equilibrium level. Our confidence intervals based on persistence profile approach for the half-lives is much narrower than previous evidence might indicate. Taken together, these results show that mean reversion is stronger than commonly thought.
\end{abstract}

Keywords: Real exchange rates; Asian economies; Structural breaks; Half-life 